\title{
A Psychological Perspective Comparing the Views of Dai Zhen (戴震) and Zhu Xi (朱 喜) On Human Nature
}

\author{
Ali Far \\ Received 21 Sep 2014 Accepted 02 Oct 2014
}

Abstract - The objective of this paper is to provide a psychological perspective on Zhu Xi (ZX) and Dai Zhen (DZ) views about human nature, by comparing the potential implications of their views on an agent's moral cultivation. To help frame this objective, I will ask and answer the following question: if one commits to $\mathrm{ZX}$ who holds the view that human nature is innately good, although obscured, versus if one holds DZ's view that while human nature has the potential for good but it is unformed or unknown (i.e., no original nature) then what are some of the possible implications for self love, sympathy, hope, forgiveness, and spontaneity that are relevant considerations, some of which have been noted by $\mathrm{ZX}$ and DZ, for the advance of an agent's moral cultivation.

The implications of ZX's commitment to human nature being innately good could entail the following: despite an agent's obscurities, because his nature is good, he is lovable and he can be hopeful that he can shed off his obscurities via proper moral cultivation. Spontaneity is encouraged as an integral part of an agent's moral self-cultivation. His self-responsibility, hinges on his ability to use the instrumentality of moral cultivation, for which he would need the assistance of a moral teacher. There is a greater capacity for forgiveness because of the presumption that the human nature is inherently good. He can sympathize and extend concern for others, in part, because others' nature is also good. ZX's view may potentially carry a risk of excess and a risk of expecting mainly the good, but not the unknown.

Alternatively, implications for DZ's commitment to no original human nature, entails the following: DZ's view is likely more conducive to expecting and embracing the unknown, which potentially makes DZ's philosophy more practical, because we live in a world where we often encounter unknowns and unfamiliar people. Self-love is a prerequisite to know love before one can love others. A moral agent can be hopeful because his potential is good, and it will not be a lost opportunity in light of the constitutive essence of moral cultivation. Despite DZ appearing to be against spontaneity, he is only against the kind of spontaneity that could be hurtful to others as does ZX. Lastly, I argue that DZ's view could result in a broader and more practical commitment to sympathy. Compared to $\mathrm{ZX}$, I argue that DZ's view could have a potential risk of lower selfresponsibility and risk of resistance to self-forgiveness, which does not arise out of DZ's views about the human nature per se, but rather stems from DZ's bias towards externalized morality.

Index Terms - Philosophical Psychology, Self Love, Sympathy, Hope, Forgiveness, Oneness, Tranquility, Neo-Confucianism, Confucianism, Dai Zhen, Zhu Xi, Chinese Philosophy, Moral Cultivation, Human Nature.

\section{INTRODUCTION}

In self-love (not to be confused with selfishness), I can have self-acceptance, self-trust, and self-respect. In sympathy, I can learn to understand and feel the world from the perspective of others. With self-love and sympathy, I can accept, respect, care for, and have love for others [1]-[3][9]. In hope, I can be optimistic despite my encounters with the unknowns and life challenges. Everyone makes mistakes, and if I can forgive myself for my mistakes, I can forgive others and believe that I too can be forgiven by others. In spontaneity that is not harmful, I can get to know myself and self-cultivate. I chose self-love, sympathy, hope, forgiveness, and spontaneity since some of such considerations have been noted by $\mathrm{DZ}$ and $\mathrm{ZX}$ as factors that matter in moral cultivation $^{1}$.

ZX viewed human nature to be innately good but obscured, which can be cleared through moral cultivation.[4] DZ viewed human nature as having the potential to be good through moral cultivation, but held that human nature is neither bad nor good (i.e., no original-nature). DX's view is closer to the idea that human nature is unformed or unknown, with a potential for goodness that can be constitutionally developed via moral cultivation.[3][4]

In summary, the objective of this paper is to answer the following question: if one commits to the idea that human nature is innately good as opposed to being unformed or unknown (but with potential for the good), then what kind of commitments arise with respect to considerations such as selflove, sympathy, hope, forgiveness, and spontaneity for one's development and moral cultivation, which are consistent with ZX's and DZ's views on human nature?

To bring this comparison into focus, it may be helpful to very briefly bring ZX's and DZ's views about desires in perspective: (a) what are ZX's and DZ's general views on desires? (b) Where could DZ and ZX agree and where could they disagree with respect to desires?

\section{A. $Z X$ and $D X^{\prime}$ 's Views on Desires:}

DZ viewed desires as integral components to moral cultivation, whereas $\mathrm{ZX}$ thought it is better to have fewer desires.[4][7] Discussions about the detailed role of desires in ZX and DZ's philosophy is outside the scope of this paper. However, due to the interplay of desire and moral cultivation, I address this question in order to frame and highlight where DZ and ZX may have a common perspective regarding

\footnotetext{
${ }^{1}$ Detailed discussions about moral cultivation and its' pertinent factors are beyond the scope of this paper.
} 
desires, despite their differences in the general view. [5] Both ZX and DZ aimed for their students to reach a tranquil and harmonious state of pattern, or principle, or the mean, or a sense of oneness.[5]-[8] A follower of ZX starts with more desires, progressively converges towards fewer and less intense desires along a journey of moral cultivation, and ideally ends up with no unmet desires (i.e., if all desires are satisfied in the state of pattern, then there remains no desires in the pattern.) but the desire for harmony in that state of pattern itself. ZX neither holds that a moral agent is best not to have any desires, nor that an agent should not have the kinds of desires that motivate his moral cultivation towards the pattern. From ZX's point of view, obscurities could distort or block an agent's real and deeper needs and desires. For example, an agent may believe that he needs or desires power of money, respect of fame, fun of elaborate parties, and excitement of fast cars. But upon awareness, he realizes that he wanted money and fame so people would notice him. He held elaborate parties and wanted fast cars so he could have the company of others and experience the thrills that could help him forget that he is alone. Upon reflections, he realizes that he just desired to be happy and be loved, and that he had an aversion to being alone. With such an awareness, his desires for wealth, fame, parties, and thrills disappeared. As such, he was left with fewer desires but more virtuous ones as in the desire for love and friendship.

From ZX's point of view, when a moral agent becomes aware, he gets in touch with his good nature from within, as the light of awareness shines away his obscurities. Alternatively from DX's perspective, through moral cultivation, an agent can develop his potential and create his good human nature. Via moral cultivation, and agent's real and deeper desires can become aligned and congruent with the good human nature that he already possessed according to ZX's view, or with his good nature that can be developed and realized according to DZ's view.

Therefore, both ZX and DZ have this view in common with respect to desires: a moral agent is motivated to reach a sense of oneness, where pattern is his desire and his desire is his pattern [4]. For both ZX and DZ, it is from the state of oneness where an agent's ultimate motivations originate. In that state of oneness, the agent responds to the world perfectly morally with ease, without effort, automatically, spontaneously, and naturally, without thought and without deliberation, where there is harmony and moderation (i.e., neither insufficient nor excessive). In the pattern the push and pull of desires are no longer, where an agent (following either of DZ or ZX views) meets joy and quietness. For both ZX and $\mathrm{DZ}$, an agent engaged in moral cultivation approaches the pattern, where and when more and more of the his desires meet satisfaction and the agent is left with fewer and fewer desires (until the pattern, where there remains no unmet desires).

In summary, because both $\mathrm{ZX}$ and $\mathrm{DX}$ agree that the ultimate goal for a moral agent is to reach the pattern, they both would likely agree with having (1) progressively fewer desires, and (2) an ideal final state of desirelessness, which is an ultimate goal of a moral agent.

\section{B. Cases that ZX and DZ could Agree about Morality or Immorality of Certain Desires}

DZ and ZX would likely agree that certain desires are immoral (i.e., desires that motivate hurting one's self or others, and let us call this the upper zone), and they would likely agree that certain desires are moral (i.e., desire to shelter and nourish self and one's family, and let us call this the lower zone). I will focus my discussions for this paper in the zone where $\mathrm{DZ}$ and $\mathrm{XZ}$ may differ and let us call this the middle zone.

It is likely that ZX and DZ would agree in rejecting desires that motivate obvious hurtful acts such as killing (not in self defense), torturing, assault, battery, (falsely) imprisoning, defaming, cheating, stealing, or other obvious hurtful actions.

Furthermore, ZX and DZ would likely agree in approving desires that motivate a person in seeking satisfaction of his basic needs such as proper nourishment, seeking shelter, and making money to provide for his needs and his family's welfare, etc. ZX and DZ would likely agree that certain basic human needs should be met before an agent can commit and be reasonably expected to progress in his moral cultivation.

Now let us designate an area where there could be potential disagreement between ZX and DZ, and call this the middle zone, where an agent may be faced with (i.e., neither the upper nor the lower zones) for example: Forgiveness in ways one deals with mistakes of self and mistakes of others; the role of hope and being loveable towards self and others; the role of self-responsibility and the interplay between caring for self and caring for others; the role of being sympathetic as opposed to unsympathetic in situations when one could be indifferent and unhelpful to others; handling conflicts within one's circle of care (i.e., with parents, children, spouse, neighbor, and governor); the point at which desires are excessive with respect to tasty vs. normal food or expensive vs. good attire or adequate vs. fancy house or ambition vs. becoming fame; or the role of spontaneity in desires and motivations in moral development.

To summarize and before I delve into the discussion section, note the following: (1) the primary aim of the next discussion section is to address the middle zone, where ZX and DZ might disagree in lieu of their different perspectives about human nature, (2) the discussion section exclude the kind of cases where ZX and DZ could likely agree upon the morality or immorality of agents desires and motivation, (3) I would assume that ZX and DZ have more in common about the kind of desires that help motivate one's moral cultivation, and that both ZX and DZ share the same ultimate, which is to have fewer unmet desires over time, and (4) there are other factors beyond self-love, sympathy, hope, forgiveness, and spontaneity that are pertinent to moral cultivation. To keep the scope of this report contained, I limit my analysis to a narrow set of considerations for moral cultivation, some of which have been noted by DZ and ZX, such as sympathy, selflove, spontaneity. 


\section{DISCUSSIONS}

\section{A. What are the Moral Cultivation Implications of $Z X^{\prime}$ 's View} that Human Nature is Good but Obscured?

ZX asserts that while man's innate nature is good, it has been obscured, which can be cleared via moral cultivation, education, and attending to certain rituals. ZX holds that moral cultivations are like instruments (to help one shed off his obscurities, gain awareness, and become congruent with his innately good nature).[4] As such moral cultivation has no constitutional role because he already possesses the good nature (e.g., moral cultivation does not create new blood as in creating more good because the person is born with all the good already; moral cultivation opens up the arteries and veins for the existing blood to flow and reach everywhere in the body).[3] Let's now address ZX's view regarding human nature, with its implications in terms of self-love, hope, spontaneity, forgiveness, and sympathy.

Self-love: Despite having an innate nature that is good, an agent has obscurities that can prevent him from living the life that is congruent with his good nature.[1] Since the good is loveable, the implication of ZX's view is that the agent can be hopeful that he is loveable (including by others) and that he can love himself.

Hope: If an agent believed that his nature is good, then he just needs to shed off his obscurities to get back in touch with the good inside himself. The consequence of such belief system is a hopeful one. Such optimistic picture could give an agent some confidence that his moral cultivations and efforts could eventually result in a sense of oneness with the his good nature, no matter what, which would likely motivate and fuel his drive not to give up until he gets there.

Spontaneity: ZX was in favor of spontaneity. A belief system such as ZXs' that views human nature as good could be more accommodating to spontaneity because proper spontaneity can facilitate moral self-cultivation, and here is how: An agent may not be consciously aware of all his obscurities and shadows. Thus, he can allow what is inside him to appear through spontaneity because (1) given that his inner nature is good, he does not need to be afraid of what is beneath his coat of obscurities; (2) although he could use a moral guide, such a teacher cannot possibly know what is inside him, thus he has no choice but to be responsible for his morality; and (3) the only way to strike out his obscurities is by shining the lights of awareness on them. Thus, spontaneity is pivotal in the progress of an agent's moral self-cultivation. Just as a reminder, this examination pertains only to the cases in the middle zone. (Spontaneity in self-evident hurtful expressions or actions are rejected by both ZX and DZ).

Forgiveness: Generally speaking, there is a greater propensity to feeling of shame if an agent believed that his nature was bad, which could likely handicap his ability to forgive. For ZX, when an agent makes mistakes, it is not because he is bad but it is because he has these obscure coats that have distanced him from his good nature. As such, it is more likely that he can forgive, believing that his and others' innate natures are good, and hence it is less likely for him to carry shame for his own mistakes or shame others for their mistakes. There is potentially less dependence (regarding his mistakes) on decrees of a moral leader. Hence, there is less likelihood of moral paralysis, if otherwise he had to await judgment of a religious leader, for example, to determine if he is good or bad or forgiven.

Sympathy: If a moral agent believed that human nature is good, he would be predisposed to also hold other people's nature as good. For one to believe in the abundance of good natured people in the world, it would help him feel safer in the world (compared to a system of belief that view people's nature as bad, for example). Such belief system in turn would more likely motivate him to be open to reach-out, connect, care for others, and belong more to the world and its people. As such, he would be more inclined to sympathize with others.[2]

Risks with ZX's view of good human nature:

(1) Risk of Excess: If an agent has a guarantee this nature is good, then is it possible that he might not try hard enough to shed off his obscurities to uncover his good nature sooner? If he believes that he is good, is there a risk that he may take being loveable for granted and become selfish? If he believes that he is supposed to have been good because of his innately good human nature, how likely is it for him to blame his caretakers for his obscurities or carry bitterness towards them, and not take responsibility? If an agent believes that others are good in nature, just like him, is there a greater risk that he might be disposed to be overly trusting or enmesh with strangers that he meets? Because an agent believes that he is good, could there be a higher tendency that he may overindulge himself by being overly spontaneous because he believes that nothing bad could come out of it. The risks of excess addressed here are for cases in the middle zone, where a serious moral agent with the belief that he possesses obscurities, could cultivate the proper internal guards against such risks and be motivated enough to stay alert and diligent to rid himself of obscurities sooner than later.

(2) Risk of anticipating only the good, not the bad, and not the unknown: There is an appeal to ZX's view that human nature is good innately. An agent can anticipate and accept himself because his nature is good. Moreover, he can anticipate and accept the good in others (who by design have good natures like his). The real world will likely present some appearance of bad and some unknown to us. Part of an agent's moral cultivation should involve the skills in anticipating and morally dealing with the appearing bad and the unknown. Is there more risk of being less equipped to (morally) deal with the unfamiliar and the unknown in ZX's belief system that believes and anticipates only the innately good human nature that may be obscured? Comparatively, while I would argue that DZ's belief system could better prepare a moral agent to embrace the unknown and the unfamiliar, committing to ZX's view does not clearly make an agent ill-equipped to do the same.

\section{B. What are the Moral Cultivation Implications of DZ's View that Although Human Nature has the Potential for Good, but it is Unformed and Unknown (i.e., has no Original Nature)?}

DZ viewed human nature as having the potential to be good: but he thought that an agent's nature was unformed and unknown in that it is not pre-determined as either good or bad. Through proper moral cultivate (constitutive) an agent could 
develop his potential and create the good. For DZ, moral cultivation, education and proper rituals can generate the good just like nutrition can generate new (good) blood in the body.[3] It is of note that DZ's view is closer to one that embraces a human nature that is more fluid, plastic, and moldable, which has a common sense appeal. Moreover, the implications of DZ's views on human nature can potentially be significant, which is to anticipate and embrace the unknown, and this point will be discussed further.

DZ held that a moral agent could not give love to others, unless he has learned to love himself. Given that DZ held that one's nature is unknown (or unformed), then one would learn not only to love himself but also to love the unknown about himself. As such, he would likely be more predisposed to be accepting and to love others whose nature is also unknown like his. It can be argued that one may be more accepting and open to what is different from us, when one has grown up in a belief system that embraces the human nature as being unknown or unformed. Outside our communities, most of the world presents itself to us as an unknown. Most people who we first meet come to us as unfamiliar, different, and as unkowns. Our ability to experience and embrace the unknown can be an indispensible resource for our moral cultivation with respect to the people we meet. One could argue that dealing with or embracing the unknown can be anxiety and fear provoking. DZ's view that human nature has the potential for good should take at least some of such anxiety or fear off the table. Some anxiety about dealing with unknowns may be a good thing for it can help fuel one's healthy tension to be more diligent in our moral endeavors involving others. Again, note that we are in the middle zone, and the fear and the anxiety about for example hurtful and harmful acts of self and others do not enter the equation of this discussion. Let's now address the implications for DZ's human nature as it pertains to selflove, hope, spontaneity, forgiveness, and sympathy:

Self-love: DZ held that one has to love himself first, before one can learn what love is, and only then he would be able give love to others.[3] As noted earlier, DZ's endorsement of self-love combined with his view about the unknown human nature (with the potential for good) can have the implications of enabling an agent to extend that kind of love to the unknowns in the outside world [1]. In real life, an agent's moral teacher is likely neither next to him all the time nor available for consultation real-time. As such, in his day-to-day affairs, an agent may be faced with matters he does not know. An agent with a belief system that human nature is unknown or unformed may develop more self-sufficient skills to interact with people he encounters who are unknown to him at first, as compared to taking a leap of faith that everyone's nature is good before he even met them. Believing to anticipate and embrace the unknown could also condition a moral agent to perhaps pause to wonder, and handle the unknown, even with appearances of good or bad, with more patience.

Hope: For any adult whose upbringing and life circumstances have conditioned him with certain belief system and character traits, should some moral teacher then wipe his past clean or build on who he is already? Following DZ, although the agent starts with an unformed nature that has the potential for the good, his potential is not the kind to "use it or lose it". Constitutive role of moral cultivation makes room for the good to grow as part of humanity's nature. Potential for good will not be a lost opportunity, and this is hopeful. Because the agent has self-love, he expects and accepts all of himself believing that it is possible that he has some unknown and good inside that can grow. Even if he may have developed some improper beliefs or traits, they can be displaced with the good via moral cultivation (which is constitutive in DZ's view), which is an optimistic and hopeful perspective about nature of humanity.

Spontaneity: Contrary to ZX's view, DZ may seem to be against spontaneity.[4] I suggest otherwise, and here is why: neither ZX nor DZ would be in favor of the kind of spontaneity that embodies hurtful others-directed (as opposed to self-directed feelings) that are reactive, unpredictable, and self-centered. DZ supported the role of desires and emotions in moral cultivation, and thus it is less likely that he would have held a broad objection towards spontaneity (which mostly applies to or is invoked by emotions)? I suggest that DZ would not likely reject the kind of spontaneity that is productive and instrumental for moral self-cultivation, but DZ would object to the kind of spontaneity that comes at the expense of hurting and harming others. Neither ZX nor DZ would endorse the kind of spontaneity that involves "rancorous emotional attitudes that are very different from the emotional harmony that neo-Confucians believed in".[8] Again, note that this examination of DZ's and ZX's views about spontaneity are centered on cases in the middle zone (not upper and not the lower zone that were framed earlier in the paper).

Forgiveness: Although an agent may not have the good nature yet, he has the potential to make his nature good. If along the way he makes mistakes, it can be because of his lack of awareness or knowledge (i.e., insufficient or improper cultivation) and hence he can be forgiven. As noted, the mistakes and their respective forgiveness discussed here apply to cases in middle zone. In lieu of the constitutive view regarding moral cultivation, an agent committed to DZ's view would likely rely more on guidance of a moral teacher to decipher the proper from the improper. Accordingly, an agent could rely more on his teacher in order to be forgiven or not. Is there a risk of moral paralysis if the agent's moral teacher is not around or does not forgive him? Could an agent here truly internalize forgiving himself or for that matter, others? It seems that the risk of lower self-responsibility and risk of greater inability to forgive self and others would not stem from DZ belief system about human nature per se, but it stems from $\mathrm{DZ}$ view that in order for the human nature to realize his full potential for the good, he might need to rely more on the guidance of a moral authority. One might argue that the instrumental role of moral cultivation in ZX's belief system could engender a very different but be proportionally as risky to the aims of self-responsibility and forgiveness.

Sympathy: From the time one leaves the womb until he enters the grave, he encounters unknowns (or things and others that are different from her).[3] As mentioned earlier, it is more likely that learning to expect, accept, and love the unknown and that which is different disposes a moral agent to be sympathetic and gain a broader commitment to othersperspective taking. Combined with DZ's view about loving one's self so to be able to love others plus the constitutive 
essence of DZ's moral cultivation, here is a natural appeal to DZ's belief system: Starting from accepting the unknown parts of one's self, an agent can be more predisposed with a natural commitment to accepting the unknown parts of others.[2][9] This can potentially enables one to, more seamlessly, expect that which is different and the unknown parts of the world including the different people he meets along the way. In this regards, DZ's view can be more equipped to facilitate the cultivation of an agent in becoming more open minded, and more sympathetic towards (i.e., the unknown or unformed natured and different) people.

In ZX's view, people are innately good in nature but possess obscurities which can be shed off, after they become aware of them. Where a moral agent starts from a core belief that other's nature is only good, then he may run the risk of expecting only the good. Comparatively, committing to DZ's view, a moral agent may be more likely disposed to embrace (and be more sympathetic with regards to) the unknown and the unfamiliar and ones who appear to be different from him.

\section{CONCLUSION}

This paper aims to provide a psychological perspective on ZX and DZ's views about human nature via comparing the implications of such view on moral cultivation. To frame this objective, the aim of this paper is to answer the following question: if one commits to ZX's belief system who holds that human nature is innately good (although obscured) versus if one commits to DZ's belief system that although human nature has the potential for the good but it is unformed and unknown (no original-nature), then what are some of the implications of those belief systems that are relevant to moral cultivation? The alignment and consistency of DZ and ZX's views about human nature and their implications are examined in terms of self-love, sympathy, hope, forgiveness, and spontaneity, which have been noted by both DZ and ZX.

For ZX's side, I hoped to have made the following case: Despite a moral agent's obscurities, because his nature is good, he is lovable and he can be hopeful that he can shed off his coat of obscurities. Spontaneity is encouraged as an integral part of his moral cultivation. His self-responsibility hinges on his ability to use the instrumentality of his moral cultivation, for which he may need the assistance of a moral teacher. There is self-forgiveness given the presumption that mistakes of an agent who is good in nature is forgivable. He can sympathize and be more forgiving with others because others' nature is also good like his. I discussed some of the possible risks with ZX's views on human nature including risk of excesses and risk of anticipating only the good, not the bad, and not the unknown.

For DZ's side, I aimed to make the case that his view is more conducive to expecting and embracing the unknown and that which is different. This aspect of DZ's view is attractive in its practicality and common sense respect, because we live in a world of mostly unknowns, where we encounter people that may appear different from us. A moral agent can be hopeful because his potential is good and it will not be a lost opportunity. Because moral cultivation is constitutive, he can develop his potential and create the good in his nature. Despite DZ being against spontaneity, I argue that DZ was only against the kind of spontaneity that may be self-centered and hurtful to others, as was ZX. Compared to ZX, I show that DZ runs the potential risk of having lower selfresponsibility and risk of greater inability to forgive one's self and others, which does not stem from DZ's views on human nature per se, but it stems from DZ bias towards externalized morality. If one does not learn to love himself, he cannot love others. Hence, self-love is a prerequisite to being able to love, care, and sympathize with others. Lastly, I argue that DZ's view about human nature could result in a more practical commitment to sympathy.

\section{ACKNOWLEDGEMENT}

I would like to express my sincere gratitude to Professor Justin Tiwald at San Francisco State University for his mentorship and invaluable feedbacks.

\section{REFERENCES:}

[1] Tiwald, J., (2011) "Dai Zhen's Defense of Self-Interest". Journal of Chinese Philosophy 38 (s): 29-45.

[2] Tiwald, J., (2011), "Sympathy and Perspective-Taking in Confucian Ethics". Philosophy Compass 6 (10): 663-674

[3] Tiwald, J, (2006), "Dai Zhen (Tai Chen, 1724-1777)", IEP.

[4] Tiwald, J, (2012). "Dai Zhen on Human Nature and Moral Cultivation." In the Dao Companion to Neo-Confucian Philosophy, ed. John Makeham (Dordrecht: Springer): Ch. 19

[5] Angle, S., Tiwald, J., (2009), "Psychological Metaphysics: Emotions and Heart-mind", Ch. 5.

[6] Zisi, "The Mean" Translators Bryan W. Van Norden. Year unknown. Actual author unknown.

[7] Ivanhoe, P. J. (2013). "Senses and Values of Oneness".

[8] Angle, S., (2003), Chapter 6: "Challenging Harmony: Consistency, Conflicts, and Status Quo", p.10

[9] Tiwald, J, (2010), "Dai Zhen on Sympathetic Concern," Journal of Chinese Philosophy, 37.1, (March 2010)

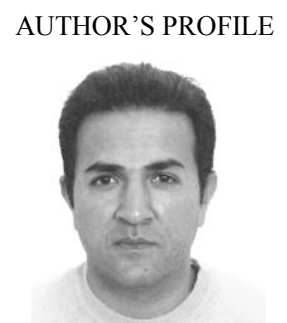

Ali Far was born in Iran in 1961. He received the B.S. in Electrical Engineering and Computer Science from UC Berkeley in 1983. He got his M.S. in Electrical Engineering in 1986, M.B.A. in 1989, Juris Doctor in Law in 1997, and M.A. in Psychology (MFT \& LPCC) in 2010, all from Santa Clara University. He is currently completing his M.A. in Philosophy at San Francisco State University. Between 1982 to 1997, Ali worked in Silicon Valley for technology companies including Plantronics, Precision Monolithics (now ADI), Micro Power (now Exar), Media Vision (now Creative Labs), and lastly for TelCom (now Microchip) where he was VP of Design Engendering. During this period, Ali developed analog semiconductor chips. Between 1998 to 2009, Ali worked at Wall Street firms including Prudential Securitas, Galleon Group, and lastly Spherix where he was Founder, and Analyst covering and investing in technology equities. Ali has 12 patents and several pending in the area of analog semiconductors. His current area of interest are Asian and continental philosophy, and philosophical psychology. 